\title{
AVALIAÇÃO DOS RESULTADOS DE UMA ESTRATÉGIA DE CAPACITAÇÃO DE PROFISSIONAIS DE SAÚDE PARA PRODUÇÃO DE CONTEÚDO PARA EAD
}

\author{
RIO DE JANEIRO/RJ JULHO/2018
}

\author{
Telma de Almeida Souza - INCA - tsouza@inca.gov.br \\ Mônica Nogueira da Costa Figueiredo - INCA - mfigueiredo@inca.gov.br \\ Márcio da Silva Camilo - INCA - marcio.camilo@inca.gov.br
}

Tipo: Relato de Experiência Inovadora (EI)

Categoria: Métodos e Tecnologias

Setor Educacional: EDUCAÇÃO SUPERIOR, EDUCAÇÃO CONTINUADA EM GERAL

\begin{abstract}
RESUMO
Esse artigo pretende apresentar os resultados da capacitação de profissionais para produção de material didático para $E A D$, desenvolvida a partir da identificação dessa demanda pela equipe de educação a distância do Instituto Nacional de Câncer (INCA). Essa análise foi realizada com o intuito de se verificar se a estratégia de capacitação implementada atingiu seus objetivos com relação à melhoria do processo de produção dos cursos online do INCA. Foi aplicado um questionário estruturado, logo após a capacitação, a fim de avaliar a opinião dos profissionais capacitados. Além disso, foram analisados os fluxos de produção de material dos dois cursos desenvolvidos após a capacitação, comparativamente com o fluxo de produção de materiais anteriores. Os resultados foram avaliados a partir da comparação entre os resultados previstos e os resultados realizados, tendo como parâmetro os indicadores definidos nos fluxos de produção. Foram analisados todos os materiais produzidos após a capacitação ter sido finalizada. Os resultados apontam que a capacitação dos profissionais não apenas contribuiu para melhoria da qualidade dos materiais produzidos, como também diminuiu o tempo de produção e as idas e vindas dos materiais para correção. Além disso, observou-se uma quebra de paradigma, enfatizando a necessidade de uma preparação especial para o material que será disponibilizado na plataforma de ensino. Conclui-se que a estratégia de capacitação teve resultados positivos, atingindo seus objetivos. A capacitação prévia dos docentes para a elaboração de material para EAD pode aumentar a qualidade dos materiais produzidos, diminuir o tempo de produção e promover o desenvolvimento e a continuidade das ações de educação a distância.
\end{abstract}

Palavras-chave: Teleducação. Capacitação profissional. 


\section{Introdução}

A incorporação das tecnologias interativas na educação na área da saúde tem apresentado resultados muito significativos. Porém, também enfrenta algumas dificuldades e suscita discussões sobre as contribuições pedagógicas e limitações vivenciadas.

A Internet trouxe para a educação a possibilidade de desenvolvimento de aulas por meio de recursos como os ambientes virtuais de aprendizagem (AVA), equipamentos de teleconferência, audiovisual, entre outros. A tecnologia permite o acesso ao conteúdo das aulas, porém, não garante a comunicação entre alunos, professores e material didático. Para isso, é necessário construir materiais com interfaces e técnicas pedagógicas que favoreçam a interação.

Desenvolver um material didático adequado para EAD passa pela necessidade de se compreender quais elementos são importantes para um processo de ensinoaprendizagem efetivo. É necessário, também, que os conteudistas entendam quais os objetivos educacionais desse material. Diante dessas questões, percebeu-se que era importante detalhar os critérios de produção de material didático para a elaboração de materiais interativos e dialógicos que possam suprir a distância física entre professor e aluno. Para permitir que o aluno desenvolva seu aprendizado, o material para EAD precisa ser autoexplicativo e bem escrito, com elementos que facilitem a compreensão sobre o conteúdo.

Nesse contexto, o profissional que irá elaborar o material deve ter a compreensão de todas as características necessárias para que a produção seja de qualidade. Diante da percepção das dificuldades que os profissionais apresentavam na produção dos materiais para EAD, desenvolveu-se uma estratégia de capacitação a fim de ofertar subsídios para aprimorar essa produção.

Esse estudo foi realizado com o intuito de se verificar se a estratégia de capacitação implementada atingiu seus objetivos com relação à melhoria do processo de produção dos cursos online do INCA.

\section{Objetivo}

Relatar os resultados da experiência da capacitação de profissionais da saúde para a produção de material didático para EAD. 


\section{Referencial Teórico}

O ensino é uma atividade que envolve três componentes: professor, aluno e conteúdo. Entre eles torna-se necessário que haja interação, que pressupõe uma ação educativa, sistemática e organizada. Exige não somente a dupla via de comunicação, mas também um processo continuado, com a escolha adequada dos meios na produção do conteúdo. Para o desenvolvimento de interfaces amigáveis é necessário que esses conteúdos sejam autoexplicativos (PORTUGAL, 2003).

Com relação aos fatores que influenciam o processo de ensino-aprendizagem a distância, o material didático é considerado como fator crítico de sucesso, sendo fundamental como mediador desse processo (STEFANELLI, 2003).

Considerando as características dos materiais didáticos para EAD, em geral, há um consenso de que não existe um único formato-padrão que sirva para todos os materiais didáticos. O formato depende do tipo de conteúdo a ser apresentado, do objetivo de aprendizagem a ser trabalhado e das características do público-alvo. Existem diversas metodologias de elaboração e organização do material didático, baseadas em variadas teorias de aprendizagem. Essas metodologias e teorias que as norteiam, se complementam, sendo cada combinação entre elas mais apropriada em determinada situação de ensino-aprendizagem (ROMISZOWSKI e ROMISZOWSKI, 2005).

$\mathrm{Na}$ saúde, atualmente busca-se aplicar estratégias de ensino e aprendizagem que envolvam a problematização e a aprendizagem baseada em problemas. São trabalhadas situações para a resolução de problemas por meio de estudos de caso. A interatividade, discussão e construção coletiva de conhecimento são abordagens utilizadas para a produção de atividades educativas. A área de saúde foi pioneira em trabalhar com solução de problemas, com experiências na década de 1960, no Canadá, havendo, hoje, uma consolidação dessas metodologias ativas (CYRINO, E.; TORALLESPEREIRA, M.L, 2004; MORAN, 2013).

À medida que docentes e discentes descobrem as facilidades do mundo virtual, aumentam também as necessidades de utilização das tecnologias em atividades didáticas. É importante e recomendável desenvolver oficinas com o corpo docente para que esses tenham contato com os recursos digitais e conheçam as ferramentas e metodologias disponíveis (TORI, 2003). 


\section{Procedimentos Metodológicos}

Para avaliar os resultados da experiência da capacitação de profissionais da saúde para a produção de material didático para EAD, foi aplicado um questionário estruturado, logo após a capacitação, a fim de avaliar a opinião dos profissionais capacitados. Dos 56 profissionais, que participaram da capacitação, 13 já produziram e entregaram materiais didáticos. Desses, 9 responderam ao questionário de opinião. O questionário apresentou questões relacionadas às contribuições trazidas pelos temas abordados na oficina; à adequação das atividades propostas aos objetivos da capacitação; à ampliação de compreensão sobre a produção de material para EAD; à capacidade de aplicação dos conhecimentos adquiridos; entre outras. Além disso, foram analisados os fluxos de produção de material dos dois cursos desenvolvidos após a capacitação, comparativamente com o fluxo de produção anterior.

Os resultados foram avaliados a partir da comparação entre os resultados previstos e os resultados realizados, tendo como parâmetro os indicadores definidos nos fluxos de produção de material do Núcleo de Educação a Distância (NEAD) do INCA. Foram analisados todos os materiais produzidos após a capacitação ter sido finalizada, sendo: os materiais didáticos dos cursos "Detecção Precoce do Câncer" e "Atualização em Enfermagem: Dor oncológica", desenvolvidos no ano de 2017. Todos os conteudistas desses cursos foram capacitados.

Partiu- se da hipótese que um material escrito por um profissional capacitado especificamente para produção de conteúdo para EAD não geraria excessivas reescritas e reenvio para o conteudista, após análise do desenhista instrucional. Logo, haveria um menor tempo para a finalização dessa etapa de produção. Além disso, acreditava-se que o material apresentaria uma forma de escrita mais dialógica, prevendo também possibilidade de interação. A análise dos questionários e fluxos foi descrita na apresentação dos resultados.

\section{Apresentação e Discussão dos Resultados}

A estratégia de capacitação para elaboração de material didático para EAD foi organizada a partir de oficinas, baseadas em metodologias ativas, enfatizando a importância da participação ativa do aluno no processo de aprendizagem. Dessa forma, além dos profissionais capacitados desenvolverem atividades práticas baseadas em metodologias ativas nas oficinas, eles foram orientados e estimulados na escolha 
dessas metodologias como norte para guiar todo o processo de construção do conteúdo. A capacitação contemplou encontros presenciais e atividades no AVA, o que contribuiu para uma melhor compreensão, por parte dos professores conteudistas, a respeito das ferramentas digitais disponíveis.

Dos profissionais que já participaram de todo processo e produziram material didático para seus cursos, $67 \%$ concordaram plenamente que os temas abordados contribuíram para a sua formação. Para $44 \%$ o conteúdo apresentou algo novo e para $78 \%$ as atividades propostas foram adequadas aos objetivos da oficina. A maioria dos participantes também concordou plenamente ter ampliado a compreensão sobre a produção de material para EAD a partir da oficina (67\%), mas apenas $22 \%$ se sentiu plenamente capaz de aplicar os conhecimentos adquiridos.

O tempo de finalização da etapa de produção do material didático, de um curso com carga horária de 50 horas, antes da capacitação era de 20 meses. Após a capacitação esse tempo de produção, para um curso com quantidade maior de conteúdo (60 horas) diminuiu para cinco meses, confirmando-se a hipótese apresentada no estudo.

Antes de a capacitação ser implementada, os materiais produzidos voltavam várias vezes para os conteudistas, para que verificassem observações e efetuassem correções sugeridas pelo desenhista instrucional. Isso ocorria até sua aprovação final, quando enfim o material era encaminhado para a etapa da revisão ortográfica. Uma das dificuldades do processo de produção era a falta de padronização para o envio de conteúdo para EAD. O material algumas vezes era enviado em arquivo Powerpoint, sem explicações complementares e ilustrações, fotos, gráficos e quadros que pudessem ser elucidativos. Havia uma crença de que poderia ser aproveitado o mesmo material utilizado para as aulas presenciais, sem que adequações para o ambiente virtual fossem realizadas. As atividades, quase sempre eram propostas na forma de questionários de múltipla escolha, algumas vezes sem apresentar ligação com os objetivos do curso ou criatividade na elaboração, proporcionando pouco estímulo ao aluno.

A análise do material encaminhado pelos conteudistas capacitados revelou características mais dialógicas e adaptadas às novas tecnologias e interfaces disponíveis no AVA, além de um cuidado maior na elaboração de textos com mais clareza para facilitar a compreensão. Essa melhora facilitou bastante o trabalho do desenhista instrucional, permitindo a diminuição do tempo necessário para a etapa de elaboração do desenho pedagógico do conteúdo dos cursos.

No questionário, os participantes apontaram a necessidade de aumentar a carga horária 
da oficina. Portanto, em 2018, a capacitação foi replanejada, acrescentando-se mais um encontro presencial. Nesse novo encontro, conteúdos como metodologia e avaliação foram aprofundados e novas atividades foram inseridas, permitindo que as experiências dos conteudistas também pudessem ser compartilhadas e trazidas como fonte de inspiração para os demais participantes.

Outro ponto importante que pode ser observado é a necessidade de maior divulgação da oficina dentro do Instituto, visto que muitos profissionais desconhecem essa oportunidade de capacitação ofertada e outras atividades realizadas pelo Núcleo de Educação a Distância. Baseado nesses resultados, uma política de comunicação e conscientização vem sendo desenvolvida, com a finalidade de apresentar essas ações.

Observou-se ainda, que alguns participantes da oficina relataram não apresentar total segurança para criar conteúdos ao término da capacitação. Porém, após participarem de fato da criação de material para os cursos, todos apresentaram conteúdos melhor elaborados, com as características enfatizadas na capacitação. Isso pode indicar que a relativa insegurança desaparece quando o profissional tem a oportunidade de colocar 0 conhecimento em prática.

\section{Considerações Finais}

O material didático tem importância fundamental como um dos fatores que interferem na qualidade dos cursos a distância. Elaborar um material que seja capaz de transmitir as informações com clareza, promover a interação e a participação e contribuir para a construção do conhecimento pelo aluno é uma importante etapa do processo de produção de um curso.

A experiência da capacitação de profissionais da saúde para a produção de material didático para EAD apresentou resultados muito positivos para o Núcleo de Educação a Distância, para os professores-conteudistas e, consequentemente, para a instituição. A capacitação prévia dos docentes para a elaboração de material para EAD pode melhorar a qualidade dos materiais produzidos, diminuir o tempo de produção e promover o desenvolvimento e a continuidade das ações de educação a distância.

O estudo permitiu reestruturar a capacitação oferecida dando mais ênfase a temas importantes como metodologia de ensino e avaliação da aprendizagem. Permitiu ainda, divulgar os resultados da experiência a fim de motivar outras equipes e instituições a desenvolver estratégias de capacitação de seu corpo-docente, para a elaboração de conteúdos de qualidade para a EAD e para uma compreensão mais clara das 
especificidades e necessidades do ensino mediado pelas tecnologias.

\section{Referências}

CYRINO, E. G., TORALLES-PEREIRA, M. L. Trabalhando com estratégias de ensinoaprendizado por descoberta na área da saúde: a problematização e a aprendizagem baseada em problemas. 2004. Disponível em: http://www.scielo.br/pdf/csp/v20n3/15.pdf. Acesso em: 17 de maio de 2018.

MORAN, J. M. Mudando a educação com metodologias ativas. 2013. Disponível em: http://www2.eca.usp.br/moran/wp-content/uploads/2013/12/mudando moran.pdf.

Acesso: 17 de maio de 2018.

PORTUGAL, C. Educação a distância: o design como agente do "diálogo" mediado pelas interfaces computacionais. Revista Brasileira de Aprendizagem Aberta e a Distância, São Paulo, Abril 2003. Disponível em: http://www.abed.org.br/revistacientifica/Revista_PDF_Doc/2003_Educacao_Distancia_D esign_Agente_Cristina_Portugal.pdf. Acesso: 17 maio 2018

ROMISZOWSKI, A.; ROMISZOWSKI, L.P. Retrospectiva e Perspectivas do Design Instrucional e Educação a Distância: Análise da Literatura. Disponível em: http://seer.abed.net.br/edicoes/2005/2005_Retrospectiva_Perspectivas_Design_Instrucio nal_Alexander_Romiszowski_Lina_Romiszowski.pdf. Acesso: 16 maio 2018

STEFANELLI, E.J. As linguagens de interação pedagógica: Reflexões sobre "Design" gráfico e instrucional - como agentes do "diálogo". Revista Brasileira de Aprendizagem Aberta e a Distância, São Paulo, Setembro. 2003.

TORI, R. O Virtual que Marca Presença. Revista Brasileira de Aprendizagem Aberta e a Distância, São Paulo, Maio. 2003. Disponível em: http://www.abed.org.br/revistacientifica/Revista_PDF_Doc/2003_Virtual_Marca_Presenc a_Continuacao_Romero_Tori.pdf. Acesso: 17 maio 2018. 